\title{
Effect of Nanoparticles on Cadmium Accumulation in Sedge (Carex Vulpina L.)
}

\author{
Radka Podlipná ${ }^{1}$, Tereza Cyrusová ${ }^{1,2}$, Tomáš Vaněk ${ }^{1}$ \\ ${ }^{1}$ Institute of Experimental Botany, Czech Academy of Sciences \\ Rozvojová 263, Prague, Czech Republic \\ podlipna@ueb.cas.cz; vanek@ueb.cas.cz \\ ${ }^{2}$ Faculty of Pharmacy, Charles University \\ Heyrovského 1203, Hradec Králové, Czech Republic \\ cyrusovt@faf.cuni.cz
}

\section{Extended Abstract}

Currently, the use of nanotechnologies is in rapid expansion, which entails increasing risks of environmental contamination by nanoparticles. Many studies describe the toxic effects on humans, but little is known about the adverse environmental effects on plants. Currently, various nanoparticles are being detected in streams, wastewater and sewage due to widespread nanoparticle uses. Many toxicological studies investigate the effect of engineered NPs on various organisms, including plants [1]. In particular, it is known that metal oxide nanoparticles, such as copper oxide nanoparticles, exert negative effects on plants[2]. On the other hand, some NPs in suitable concentrations can enhance plant growth and could be used as nanofertilizers in agriculture to increase yields and thus decrease environmental pollution caused by classical fertilizers [3-6]. The biological effects of individual metals are more or less known, but even though combinations of xenobiotics are common in nature; their combined effects still need to be thoroughly investigated. Cd frequently accompanies $\mathrm{Zn}$ minerals in the environment [7], and due to their chemical similarity they both can be taken by plants as divalent cations. It is well-known that metals in mixtures may act independently or interact to produce additive, synergistic, or antagonistic effects [8]. We have studied the accumulation of cadmium simultaneously with metal oxide nanoparticles or with their bulk counter particles by wetland plant species (Carex vulpina).

The plants were cultivated in vitro on liquid $\mathrm{RH}$ medium [9] supplemented with cadmium $(5,62 \mathrm{mg} / \mathrm{l}) \mathrm{and} \mathrm{ZnO}$ $(10,50,100$ and $200 \mathrm{mg} / \mathrm{l})$ or $\mathrm{CuO}(10 \mathrm{mg} / \mathrm{l})$ in both nano and bulk form and corresponding metal salt. Metal salts were used in the concentrations that the final amount of metal contained in metal oxide was similar to the amount of metal contained in metal salt. After three weeks the plants were harvested and the amount of $\mathrm{Cd}, \mathrm{Zn}$ or $\mathrm{Cu}$ were established by AAS in roots and leaves separately. The concentrations of photosynthetic active pigments were measured. The plants cultivated on zinc oxide accumulated the same amount of zinc independently on the form. When we compared the effect of nano and bulk zinc metal oxides on cadmium uptake there was no differences. But small amount of zinc in all forms in the medium increased the accumulation of cadmium in roots, but decreased the translocation to the leaves. On the other hand the higher concentration of zinc $(200 \mathrm{mg} / \mathrm{l})$ caused decrease in concentration of cadmium in roots and increase amount of $\mathrm{Cd}$ ions in leaves. In the case of copper, the higher concentration of $\mathrm{Cu}$ was found in plants cultivated on medium supplemented by $\mathrm{CuO}$ in nanoform; on the other hand in these plants the smaller amount of cadmium was up taken by roots and translocated to the leaves.

This study was supported by projects MYES of CR n. LD14100.

\section{References}

[1] Y. O. Konotop, M. S. Kovalenko, V. Z. Ulynets, A. O. Meleshko, L. M. Batsmanova, N. Y. Taran, "Phytotoxicity of colloidal solutions of metal-containing nanoparticles," Cytology and Genetics, vol. 48, pp. 99-102, 2014. 
[2] A. K. Shaw, S. Ghosh, H. M. Kalaji, K. Bosa, M. Brestic, M. Zivcak, Z. Hossain, "Nano-CuO stress induced modulation of antioxidative defense and photosynthetic performance of Syrian barley (Hordeum vulgare L.)," Environmental and Experimental Botany, vol. 102, pp. 37-47, 2014.

[3] K. Jeyasubramanian, U. U. G. Thoppey, G. S. Hikku, N. Selvakumar, A. Subramania, K. Krishnamoorthy "Enhancement in growth rate and productivity of spinach grown in hydroponics with iron oxide nanoparticles," Rsc Advances, vol. 6, pp. 15451-15459, 2016.

[4] E. Masarovicova, K. Kral'ova "METAL NANOPARTICLES AND PLANTS," Ecological Chemistry and Engineering S-Chemia I Inzynieria Ekologiczna S, vol. 20, pp. 9-22, 2013.

[5] R. Liu, R. Lal "Potentials of engineered nanoparticles as fertilizers for increasing agronomic productions," Science of the Total Environment, vol. 514, pp. 131-139, 2015.

[6] M. M. Rui, C. X. Ma, Y. Hao, J. Guo, Y. K. Rui, X. L. Tang, Q. Zhao, X. Fan, Z. T. Zhang, T. Q. Hou, S. Y. Zhu "Iron Oxide Nanoparticles as a Potential Iron Fertilizer for Peanut (Arachis hypogaea)," Frontiers in Plant Science, vol. 7, 2016.

[7] S. M. Ullrich, M. H. Ramsey, E. Helios-Rybicka, "Total and exchangeable concentrations of heavy metals in soils near Bytom, an area of $\mathrm{Pb} / \mathrm{Zn}$ mining and smelting in Upper Silesia, Poland," Applied Geochemistry, vol. 14, pp. 187-196, 1999.

[8] K. L. Wilde, J. L. Stauber, S. J. Markich, N. M. Franklin, P. L. Brown, "The effect of pH on the uptake and toxicity of copper and zinc in a tropical freshwater alga (Chlorella sp.)," Archives of Environmental Contamination and Toxicology, vol. 51, pp. 174-185, 2006.

[9] J. P. Nitsch, C. Nitsch, "IN VITRO FORMATION OF FLOWERS IN A SHORT-DAY SPECIES - PLUMBAGO INDICA L," Annales De Physiologie Vegetale, vol. 7, 251-\&, 1965. 